\title{
Pressurized Fluid Extraction
}

\author{
Lane C. Sander \\ National Institute of Standards and Technology, \\ Gaithersburg, MD 20899, USA \\ lane.sander@nist.gov
}

Video DOI: http://doi.org/10.18434/T4DK5T

Key words: accelerated solvent extraction; ASE; environmental analysis; extraction; PFE; quantitation; sample matrix; sample recovery.

Accepted: December 1, 2016

Published: January 12, 2017

https://doi.org/10.6028/jres.122.007

\section{Summary}

Pressurized fluid extraction (PFE) is one of several sample preparation methods that can be used to extract targeted analytes from a sample matrix into a solvent, to permit subsequent analysis. With PFE, samples are extracted with solvent in a pressurized cell reminiscent of a liquid chromatographic column. Samples are placed in the cell body along with an inert granular matrix. Solvent is pumped into the cell until it is filled, and then allowed to equilibrate under static conditions. After a predetermined time, the extract is pumped out of the cell and is collected for analysis. Environmental parameters can be controlled, and multiple re-extractions of a sample can be programmed. This presentation will provide an introduction to the practice of pressurized fluid extractions, and will demonstrate the technique for a typical sample. ${ }^{1}$

\footnotetext{
${ }^{1}$ Contribution of the National Institute of Standards and Technology. Not subject to copyright. Certain commercial equipment, instruments, or materials are identified to specify adequately the experimental procedure. Such identification does not imply recommendation or endorsement by the National Institute of Standards and Technology, nor does it imply that the materials or equipment identified are the best available for the purpose.
} 